\title{
Os Refugiados e a fragmentariadade das normas de Direito Internacional. $O$ cenário complexo das migrações forçadas face o cenário sócio-político atual
}

Los Refugiados y la fragmentaria de las normas de Derecho Internacional. El escenario complejo de lãs migraciones forzadas frente al escenario socio político actual Refugees and the fragmentary rules of international law. The scenario of complex migrations against the current socio-political scenario

\author{
Saddam Mohamad Harb ${ }^{1}$ \\ Raquel Fabiana Lopes Sparemberger ${ }^{2}$
}

\begin{abstract}
Resumo
O presente trabalho tem como objeto de estudo, o direito internacional dos direitos humanos, trazendo como proposição a apresentação da fragmentaridade do direito internacional. Muito diferente das normas internas a qual regem-se por uma hierarquia normativa, em âmbito internacional não vemos a mesma coisa, ocorrendo a horizontalidade das normas, fazendo com que as normas internas de cada estado se sobreponha, muitas vezes, as leis internacionais. Tal fato acarreta em algumas restrições a jurisdição internacional, o qual será evidenciado pela problemática dos refugiados sírios na atualidade, temática de grande relevância nos últimos anos no cenário internacional pela expressiva abrangência de seus fluxos, pelo desrespeito a dignidade humana e pela crescente violência na sua contenção, apesar de sua condição de extrema vulnerabilidade. Metodologia. Adotar-se-á o método de abordagem dialético e a técnica de pesquisa bibliográfico.
\end{abstract}

Palavras-chave: Direitos Humanos, Direito Internacional, Fragmentação e Refugiados.

Resumen

El presente trabajotiene como objeto de estúdio el derecho internacional de los derechos humanos, trayendo como proposición la presentación de la fragmentación del Derecho Internacional. Muy diferente de las normas internas a las que se rige por una jerarquía normativa, a nivel internacional no vemos lo mismo, ocurriendo la horizontalidad de las normas, haciendo que las normas internas de cada Estado se superponen a menudo las leyes internacionales. Este hecho acarrea en algunas restricciones lajurisdicción internacional, el cual será evidenciado por la problemática de los refugiados sírios em la actualidad, temática de gran relevância em los últimos años enel escenario internacional por la expresiva cobertura de sus flujos, por el irrespeto a la dignidad humana y por la creciente violência em su situación. Contención, a pesar de su condición de extrema vulnerabilidad. Metodología. Se adoptará el método de abordaje dialéctico y la técnica de investigación bibliográfica.

Palabras claves: Derechos humanos, derecho internacional,fragmentación, refugiado

\footnotetext{
${ }^{1}$ (Aluno da graduação do curso de Direito da Universidade Federal de Rio Grande (FURG) Maior Titulação; Rio Grande, Rio Grande do Sul, Brasil; Saddam.mh@gmail.com.).

${ }^{2}$ Pós-Doutorado em Direito pela UFSC, Doutora em Direito pela UFPR, professora adjunta do Programa de Mestrado em Direito e do curso de graduação da Faculdade de Direito da Universidade Federal do Rio GrandeFURG, orientadora do presente trabalho.
} 


\begin{abstract}
The present work has as object of study the international right of the human rights, bringing like proposal the presentation of the Protection of the International Law. Very different from the internal norms to which it is governed by a normative hierarchy, at the international level we do not see the same, occurring the horizontality of the rules, making that the internal norms of each State overlap with international standards. This fact will be an obstacle to the international crisis, which will be evidenced by the problem of the Syrian refugees in the current situation, the subject of great re-enactment in recent years in the international scenario because of the expressive coverage of their flows, due to respect for human dignity and for the growing violence and discrimination, despite the extreme vulnerability. The method of approach will be adopted and the technique of bibliographic research.
\end{abstract}

Keywords : Human rights, international law, fragmentation, refugee

\title{
1. Introdução
}

Fugir da violência. Vencer a miséria. Ter a insegurança da travessia do mar mediterrâneo como alternativa. Contar com a benevolência de estados autointitulados democráticos. Definitivamente, a busca por esperança renova-se a cada dia. O contingente de fluxos migratórios aumentou maciçamente nos últimos anos. As notícias veiculadas sobre deslocamentos forçados vêm comovendo a comunidade internacional, principalmente reportagens sobre crianças mortas afogadas durante a travessia.

Talvez a maldade tenha lógica própria. Certo é que o planeta conta, hoje, com cerca de 9 milhões de refugiados ${ }^{3}$. Número que demonstra bem mais que a lógica emigracionista, mas a dinâmica pela busca por dignidade e paz. As guerras que acarretaram na leva de sírios angustiados, do ponto de vista político, não trouxe maiores novidades, apenas demonstrou que as nações mais ricas se guiam conforme seus interesses. Entretanto, sob a ótica jurídica, escancarou uma problemática surpreendente, qual seja, a fragmentaridade das normas internacionais.

A crescente do número de refugiados no mundo, entre 1951 e 2015 fatores desencadeadores de conflitos e perseguições, ao longo de sua história de proteção aos refugiados, destaca que no seu contexto de formação, em 1950, os esforços concentrados eram na proteção de refugiados provenientes do fascismo e do stalinismo. Porém, nas últimas décadas, os conflitos armados, principalmente, no Oriente Médio durante e após a Primavera Árabe, elevaram os números, conforme gráfico abaixo ilustrado:

\footnotetext{
3 PIOVESAN, Flávia Cristina. Sistema internacional de direitos humanos. I Colóquio Internacional de Direitos Humanos. São Paulo, Brasil, 2001. p. 56.
} 


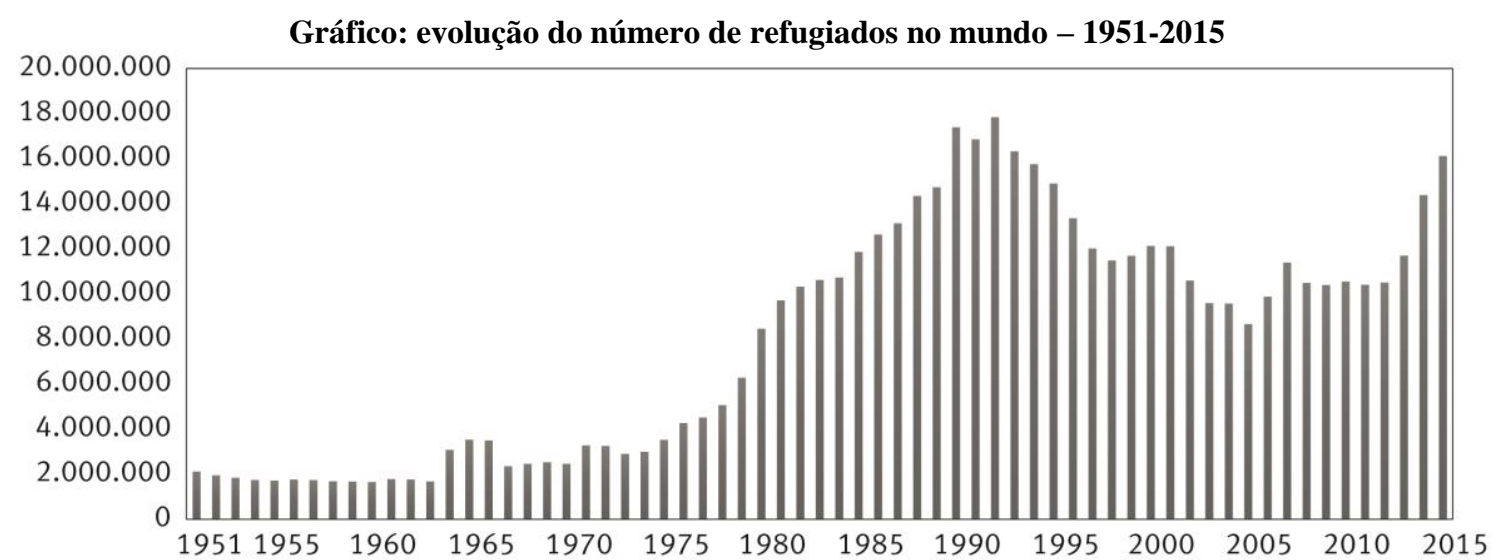

Fonte: United Nations High Commissioner for Refugees - UNHCR, Population Statistics Data Overview de 2016. Nota: Os dados referem-se, apenas, aos refugiados sob proteção do UNHCR

Muito diferente das normas internas a qual regem-se por uma hierarquia normativa, em âmbito internacional não vemos a mesma coisa, ocorrendo a horizontalidade das normas, fazendo com que as normas internas de cada estado se sobreponha, muitas vezes, as leis internacionais.

Atualmente, os debates em torno da temática dos refugiados têm como gênese o desrespeito. O Estatuto dos Refugiados destaca-se como normatividade capaz de destoar da lógica instaurada, na qual cada estado visa seus próprios interesses, utilizando como argumento principal suas leis internas. Assim, o Estatuto do Refugiado deveria ser um elemento norteador e principalmente de garantia, desde a massificação da irregularidade da migração imposta por diferentes países, sendo alvo de tentativas de restrições e revisões quanto à sua integridade e legitimidade, conforme destacado por Jorge Luiz Braga: "Hoje, toma conta de diversos países um discurso político que condena qualquer forma de migração, e que, inclusive, deseja revisar alguns pontos do Estatuto dos Refugiados, como ficou claro no discurso de posse, proferido em 1998, da presidência rotativa da União Europeia, cujo representante pertencia a Áustria, que afirmou de forma contundente, a necessidade de se alterarem as normas que concedem o refúgio, alegando que ele vem sendo utilizado por pessoas que não se encaixam na sua descrição legal (BRAGA, p. 15, 2011).”

A pretensão deste trabalho consiste em demonstrar as consequências de se ter normas internacionais cuja produção se dá de maneira descentralizada. O panorama sócio-político atual requer uma nova demanda de legitimidade do Direito Internacional. O indivíduo, enquanto sujeito de direitos no âmbito da ordem jurídica internacional, recebe a garantia de proteção do direito internacional público, que não conhece delimitação territorial.

Por isso, este trabalho trata da problemática dos refugiados Sírios frente a fragmentaridade do Direito Internacional. O tema da migração e a relação com a questão dos 
direitos humanos, inclusão e recepção é recente. Apenas na década de 90 do século XX foi firmado preeminente instrumento jurídico internacional sobre o tema como a Convenção Internacional sobre os Direitos dos Trabalhadores Migrantes e suas famílias de 1990, resultado da inquietação com a progressiva descortesia aos direitos dos refugiados, migrantes, imigrantes.

De fato, a despeito dos avanços na implementação dos direitos humanos desde a Segunda Guerra Mundial, a dignidade dos refugiados não é respeitada. Presencia-se agressões, abusos e ataque contra os que por condições alheias a sua vontade veem-se obrigados a deixar seu país e seu território.

Os números e os noticiários do início deste século retratam a proporção de uma tragédia humana que se desenrola em todos os países do mundo: há 191 milhões de migrantes internacionais e esse número tende a crescer. Os refugiados mudam-se de um território a outro, principalmente a procura de melhores condições de vida. Muitos migram como resposta as razões que os coagem a mover-se para sobreviver e propiciar segurança, dignidade e bem-estar a si e suas famílias. A causa e efeito de um mundo capitalista e extremamente dependente da exploração do suor alheio para a sua sobrevivência.

Muito diferente das normas internas a qual regem-se por uma hierarquia normativa, em âmbito internacional não vemos a mesma coisa, ocorrendo a horizontalidade das normas, fazendo com que as normas internas de cada Estado se sobreponha, muitas vezes, as leis internacional. Tal fato acarreta em algumas restrições a jurisdição internacional, o qual será evidenciado pela problemática dos refugiados sírios na atualidade, temática de grande relevância nos últimos anos no cenário internacional pela expressiva abrangência de seus fluxos, pelo desrespeito à dignidade humana e pela crescente violência na sua contenção, apesar da sua condição de extrema vulnerabilidade.

O primeiro capítulo versará sobre a dinâmica de surgimento dos refugiados nos tempos atuais, abordando os principais enfoques políticos que envolvem o Oriente Médio. $\mathrm{O}$ segundo tópico, destinar-se-á a demonstrar a horizontalidade das diversas normas internacionais, demonstrando as principais consequências da fragmentaridade do direito internacional, bem como o permanente conflito com o conjunto normativo interno de cada Estado.

\section{Aspectos históricos-políticos e o surgimento dos refugiados.}

$\mathrm{O}$ século $\mathrm{XX}$, em seu mais amplo sentido, foi testemunho de ao menos cinco relevantes acontecimentos históricos na qual o Oriente Médio foi protagonista: A dissolução 
do califado em Estambul em 1924, a criação do Paquistão em 1947, a revolução islâmica no Iran por volta de 1979, a atravancada ascensão democrática de um partido muçulmano na Argélia em 1991, e os atentados terroristas de 11 de setembro, na qual a grande mídia afirma ser de autoria de um grupo ideológico muçulmano. Definitivamente, este último acontecimento obteve êxito em transformar a visão dos ocidentais sobre a figura do muçulmano.

Diante de todo este panorama caótico na qual as grandes mídias, na pessoa das grandes empresas de comunicação, tendem a divulgar informações cuja finalidade abarque os interesses das classes abastadas, os grupos sociais, em que os muçulmanos enquadram-se e por isso não possuem poder político e econômico, inúmeras vezes, são retratados de maneira distorcidas resultando na criminalização de suas manifestações de resistência.

A Primavera Árabe ${ }^{4}$, termo ao qual ficaram conhecidos os movimentos nos países do Oriente Médio e Norte da África a partir do final de 2010 deste século levou à deformação das relações de forças políticas internas de cada país, e também em relação à diplomacia local, ou em relação à intervenção de potências estrangeiras aos entraves que surgiram nesse contexto. A principal consequência política obtida foi a queda, pela força e vontade do povo, de regimes ditatoriais que em alguns casos perduravam mais de 50 anos, o que não significou a melhoria da qualidade de vida da população, muito pelo contrário, após a queda dos regimes longínquos, o que se observou foi a instabilidade e vulnerabilidade política, culminando nas intervenções militares como desculpa para amenizar a violência.

Na Síria ${ }^{5}$, objeto deste artigo, observou-se que o país fora usado como laboratório de experimentos, na qual Estados Unidos ${ }^{6}$, inicialmente auxiliaram militarmente com armas de grande porte milícias opositoras do regime de $\mathrm{Assad}^{7}$, o que consequentemente aumentou o nível do conflito, elevando a patamares assustadores o número de mortes e o desejo de fugir.

A situação dos países que perpassaram pela floração tardia dos movimentos da primavera não era das melhores. Esta análise se faz imperiosa, pois visa demonstrar a

\footnotetext{
${ }^{4}$ Rogeiro refere três elementos que poderiam reavivar a violência no mundo muçulmano: existência de movimentos de contestação a poderes despóticos; questões pós-coloniais mal resolvidas; e luta pela libertação nacional ou resistência a ocupantes estrangeiros.(Rogeiro: 2011, 20-21)

${ }^{5}$ Síria é o país do Oriente Médio, republicano, colonizado pela França adquirindo sua independência apenas em 1946. Disponível em:< http://www.herzliyaconference.org/_Uploads/2590Bashars.pdf > acessado em 20 de março de 2017.

6 Extraido de <http ://www .bbc.com/ portuguese/ noticias/2014/08/140825_ financiamento_estado islamico_lgb> acessado em 15 de Janeiro de 2017

${ }^{7}$ Bashar Hafez al-Assad é o atual líder de estado Sírio, em uma ditadura que dura mais de 40 anos. Hafez, pai de Assad tomou o poder com um golpe militar, em 1971. Bashar al-Assad herdou a liderança do pai em 2000. Não era o próximo na sucessão, mas assumiu porque seu irmão mais velho, Basil, morrera num acidente de carro em 1994. Disponível em:< http://www.herzliyaconference.org/_Uploads/2590Bashars.pdf> acessado em 20 de março de 2017.
} 
situação da população e os incentivos para a revolta de protestos. Um dos grandes cronistas sobre o oriente Médio, Brancoli (2013, p. 45-46), surpreende com seus relatos do episódioestopim:

\begin{abstract}
“(...) pela sétima vez em duas semanas, uma policial confiscou a banca de legumes de um jovem tunisiano, Mohamed Bouazizi. (...) nas ultimas ocasiões em que tinha sido apreendido, apenas foi liberado mediante pagamento de propina. Ao tentar reaver novamente os itens, o vendedor teria recebido um tapa no rosto, dado por uma agente, que, além da agressão física, utilizou frases para humilhar o pai do tunisiano, morto quanto Bouazizi tinha três anos. (BRANCOLI, 2013, p. 45-46)".
\end{abstract}

Direcionado a discussão para a Síria, na economia, foram aplicadas um conjunto de medidas de cunho liberal, que tinham como fim o crescimento comercial e industrial, sem que o mesmo significasse o abandono das políticas de promoção de igualdade social do partido Baath $^{8}$. Entretanto, o que se verificou foi o controle econômico por componentes do regime e de figurantes ligados ao mesmo, configurando o que se denomina por "capitalismo dos amigos" (DELMONTE, 2011, 226-227). Instantaneamente, viu-se ao aumento da corrupção e ao surgimento de verdadeiros impérios econômicos controlados por agentes do regime. É de se ver que o ambiente em que aflorou-se a revolta tenha elementos de corrupção e de abuso de poder, típicos de regimes autoritários.

Ainda, quando na cidade de Deraa, cerca de 20 (vinte) jovens são presos e torturados por rabiscarem na parede de um colégio palavras em incentivo às manifestações que estavam por ocorrer no Egito e na Tunísia (GELVIN, 2012, p.103). Este acontecimento revoltou de tal forma, as populações que, em alguns dias, deflagraram movimentos em várias cidades do país. Inicia ai, uma disputa em alternância, o governo usa da violência para reprimir as primeiras manifestações, o que teve como efeito oposto, o surgimento da violência por parte dos manifestantes. As manifestações tornam-se tão fortes que o governo não consegue dar resposta aos incidentes, quando consegue atenuar um foco de protesto, em seguida surge outro.

Ademais é de se pautar as consequências da crise humanitária Síria sobre os refugiados palestinos e a minoria judaica que reside no país. A temerosa situação sub humana na Síria tem consequências negativas, principalmente, no que faz referência à população palestina, a qual, tal e qual foram toda sua história geopolítica e diplomática, vê-se como um povo na qual seus anseios e requerimentos rumam ao desconhecido, em um lócus desprovido de perspectiva futura.

\footnotetext{
${ }^{8}$ Partido de promoção de Bashar Al-Assad .
} 
Na guerra da Síria, a qual já perdura por seis anos, teve como pleito inicial o fim da corrupção e reformas políticas e econômicas. É interessante notar como os primeiros protestos aconteceram nas regiões marginalizadas por uma década de políticas liberalizantes. Damasco e Alepo, cidades as quais se beneficiaram da liberalização econômica foram pouco afetadas, identificando-se pequenos protestos. Entretanto até o momento o conflito estabelecido entre soldados opositores e o ditador Bashar Al Assad permanece sangrento, sob o olhar indiferente da comunidade internacional. A ineficaz atividade do Estado de reprimir os focos dos protestos conduziu o país a uma situação verdadeiramente calamitosa, convergindo-se em uma completa desestruturação de toda a vida social, seguida de enormes perdas humanas e de destruição do patrimônio nacional que dificultam a recuperação futura do país.

Essa evidência nos remonta para uma análise mais profunda sobre o fato de os refugiados preferirem a morte na travessia do mar Mediterrâneo ao permanecer no seu país. Seria um tanto menos doloroso no sentido de que a perplexidade diante da morte por afogamento seja menos horrenda do que ter o corpo decapitado ou ser vítima de um bombardeio perpetrado pelos radicais islâmicos. Sem contar que a aventura sobre o mar representa a luta pela sobrevivência dos refugiados, na qual a alternativa à fuga seria a morte. Em suma, a lógica da necessidade na qual as opções nem sempre são tão agradáveis.

\section{As consequências da fragmentaridade do Direito internacional - análise a partir do aumento do fluxo de refugiados}

Esta parte do artigo tem por escopo refletir sobre a horizontalidade das diversas normas internacionais, demonstrando as principais consequências da fragmentaridade do direito internacional, e o embate com o direito interno de cada estado. Comecemos por problematizar: Todos sabemos que o fluxo migratório de refugiados traz consigo, para o estado que o acolher, muito mais despesas financeiras do que benefícios. Ainda, sabendo que perpassamos por um período de crise econômica mundial, fica o questionamento: qual a probabilidade de um estado receber esta leva de pessoas, que provavelmente acarretaram em decréscimos financeiros, se ele não é obrigado a isso? Se as normas de Direito Internacional não são hierarquicamente superiores às normas de direito interno, qual a probabilidade de um estado utilizar sua norma interna para defender os interesses econômicos de seu país?

As conclusões sobre a premissa "Causas e consequências da fragmentação do Direito Internacional" poderão nos auxiliar nas respostas para as perguntas acima elencadas. A existência de uma multiplicidade de sistemas e regimes autônomos tornam o direito 
internacional contraditório e inaplicável, muito por culpa da descentralização da produção normativa.

A ausência de hierarquia é questão fundamental na abordagem do direito internacional. Mesmo que atualmente, organizações multilaterais como a Organização das Nações Unidas detém relevante função na implantação de regras comuns ao convívio dos sujeitos de direito internacional. Seria impossível identificar um órgão centralizado possuidor de responsabilidades legislativas emanadas de um texto legal fundamental, tal qual e de forma tão coercitiva quanto à constituição e as instituições que garantem eficazmente o cumprimento de suas regras e princípios no ordenamento interno dos Estados. Sob uma óptica Kelseniana, seria correto afirmar que a intenção do autor seria uma aproximação do Direito Internacional aos critérios propostos pela racionalidade jurídica positivista, pois a teoria pura não estrutura a existência de uma unidade, mas mais precisamente, uma hierarquia de normas a serem obedecidas, na qual o ponto crucial de validade seria o valor que a norma hierarquicamente superior adquire. (KELSEN, 99, p. 1234)

Portanto, coexistência de numerosas jurisdições virtualmente capazes, em um primeiro momento, culmina em impossibilitar o alcance de solução. É um fraco consolo, mas ajuda a aguardar pela criação de uma instância com jurisdição obrigatória, mesmo que supletiva, no contexto da proteção dos refugiados. Entretanto, o que se observou das práticas contemporâneas foi uma maior interdependência entre os Estados na qual teve como resultado de um Direito Internacional mais fragmentado, e na maioria das vezes, refém, das normas internas de cada Estado.

A preocupação com o os refugiados, apesar de antigo, passou a ganhar relevância na segunda metade do século passado, especialmente depois da segunda grande guerra, e mais recente com a crise do petróleo e de desastres oriundos da corrida imperialista descaradamente disfarçada por uma "falsa intenção de democratizar alguns países do Oriente Médio", levada a cabo por Estados Unidos e auxiliado pela União Européia. Nesse instante histórico, emerge os efeitos colaterais oriundos das intervenções aos quais protagonizaram as "Grandes Nações", além de demonstrar que, democracia, não foi à verdadeira intenção das potências interventoras.

Todavia, nosso amplo rol de direitos fundamentais, presente nas esparsas normas internacionais, como o art. 33 da Convenção de Genebra de 1951 na qual positiva a proibição de rechaços, carece de efetivação. Os Chefes de Estados tem falhado na implementação de 
tais direitos ${ }^{9}$. Nesse cenário, surge a necessidade de refletirmos sobre como pode o Estado, ente a quem cabe por definição a busca do bem comum, ignorar a situação de pessoas vitimas de um sistema capitalista ganancioso e claramente insustentável. Assim, identifica-se uma intenção dos chefes de Estados em desvencilharem-se desta problemática. Não foi desprendido de sentido ou fatos que Zigmmunt Bauman atribui aos refugiados a qualidade de "produtos rejeitados pela globalização", pois, apesar da Convenção de Genebra vedar a expulsão dos refugiados, a grande mídia noticia amplamente as inúmeras expulsões, bem como violência as quais os recém chegados são submetidos ${ }^{10}$.

A relativização da existência do dever do pais/nação de receber refugiados, justificada pela prevalência da soberania estatal, reforça o peso dos interesses políticos nas decisões relativas à concessão de refúgio. Assim, observou-se um equacionamento do custo - beneficio a qual norteia o acolhimento a refugiados, pois, enquanto a similaridade cultural imperava, supriam demandas de mercado de trabalho, vagas em que nativos consideravam insalubres. Ainda, eram bem vindos quando chegavam em números administráveis, os benefícios superavam os custos, resultando em políticas favoráveis à recepção. No entanto, essa conjuntura modificou-se em décadas posteriores. (FELLER, 2001, P. 149)

A horizontalidade das normas acaba por não gerar o dever de recepção, mas a possibilidade. $\mathrm{O}$ acolhimento de refugiados no contexto posterior à II Guerra objetivava atender a interesses pré - determinados dos países ocidentais. Havia interesses tanto de caráter econômico, já que a Europa atravessava um período de reestruturação e precisava de mão-de-obra barata e abundante para suprir seu mercado de trabalho, quanto de cunho político - ideológico e geoestratégico, pois se denunciava a fuga bem como a aversão de pessoas de países governados por regimes comunistas, com o intuito de desacreditar o bloco soviético e deslegitimar seus ideais. Durante a Guerra Fria, os Estados Unidos mantiveram uma política para refugiados altamente seletiva que privilegiava seus interesses de política externa em detrimento de preocupações humanitárias. Como conseqüência, indivíduos fugindo de países comunistas facilmente eram reconhecidos como refugiados, enquanto aqueles que fugiam de países aliados quase nunca tinham sua condição reconhecida. Assim, o impedimento de devolver refugiados para países onde estavam sendo ameaçados de perseguição ou foram efetivamente perseguidos foi desrespeitado quando outros interesses estatais estavam em jogo.

\footnotetext{
9 Extraido de: https://oglobo.globo.com/mundo/paises-da-uniao-europeia-violam-tratados-em-comum-aorecusarem-refugiados-17386579 acessado em 20 de Setembro de 2017.

${ }^{10}$ BAUMAN, Zygmunt. Vidas Desperdiçadas. Rio de Janeiro, Jorge Zahar Editor: 2005; p.84
} 
Sob uma óptica filosófica, encontramos em Karl Marx uma abordagem esclarecedora e ao mesmo tempo pessimista. Ao tecer considerações sobre o Estado burguês, o filósofo, em Critica a filosofia do Direito de Hegel, afirma que

\footnotetext{
"o Estado representa a visão egoísta de satisfazer interesses pessoas, os quais fundamentam a sociedade burguesa. É a sociedade que faz com que todo homem encontre noutros homens não a realização de sua liberdade, mas ao contrário, a limitação dela". (MARX, 1983, p. 130).
}

Evidentemente que o filosofo alemão não possuía qualquer intenção de fazer referencia a situação de pessoas em condições de fuga de seu país de origem. Entretanto, por analogia, suas criticas encaixam-se perfeitamente a condição sócio-política dos refugiados, na qual, os Estados Europeus, por serem igualmente burgueses, e principal foco de muitas pessoas refugiadas, materializa-se como ente limitador de liberdade, quando, deveria agir de maneira contraria.

A possibilidade de cumprimento de um preceito legal oriunda de um processo de formação descentralizado gera um lacuna jurídica que beneficia os Estados - Nação, pondo em segundo lugar a situação calamitosa dos campos de refugiados, assim como de pessoas rechaçada. O Direito Internacional dos Refugiados sempre prosperou de maneira resoluta, racional e firme, a todo o momento a busca de novos espaços humanitários, em um mundo cada vez mais fechado, xenófobo e securitizado. As Grandes Nações, na tentativa de se eximir da responsabilidade para com pessoas em situação de fuga, afirmam que as possibilidades de busca de novos espaços humanitários são vastas, mas obviamente não o são, e as crises de refugiados tornam-se cada vez mais emergentes e percebidas como ameaças iminentes.

\section{Considerações Finais}

Assim sendo, essas questões que envolvem os refugiados aflora como uma inquietação internacional no contexto atual, ante a imensa porção de pessoas deslocadas na Europa. Na Síria, como evento estopim, tivemos a Primavera Árabe, na qual o objetivo principal era por fim a um regime autoritário e corrupto. No entanto, a revolto assumiu proporções imprevisíveis, que com a crescente do Fundamentalismo Islâmico, e as intervenções Internacionais, resultaram no custo humanitário imprevisível.

Assumindo que a crise humanitária e a violência gradam de forma crescente, a migração se torna uma necessidade. Mesmo que as pesquisas provenientes de censos atestem a quantidade alarmante de mortes por afogamento no mar Mediterrâneo, a alternativa a isso, 
seria morrer de fome, em condições sub-humanas, na qual a dignidade humana seria descartada.

A angustia e o medo foram as duas sensações responsáveis pelas maiores reviravoltas históricas da humanidade, seja em tempos remotos como, por exemplo, no século XVIII, ou ainda em tempos muito antigos como na Idade Média. Atualmente, estes sentimentos assombram os árabes residentes na Síria, fazendo com que lancem-se ao mar, em busca de paz, mas principalmente, de dignidade, como se o mar Mediterrâneo fosse o arcabouço de esperança. O refúgio de sossego em que pessoas inocentes buscam face o cenário de terror que emerge nos nossos dias. $\mathrm{O}$ momento de tormento em que o pai deixa seu filho cair no mar e se afogar, morrendo lentamente no frio e na escuridão, provenientes de um mundo egoísta e intolerante. As centenas de crianças mortas afogadas representam um grande aviso ao ocidente da culpa que este carrega, e a história nos mostra que a Europa e os Estados Unidos não são inocentes.

A horizontalidade das normas acaba por não gerar o dever de recepção, mas a possibilidade. Esta dita "possibilidade" de cumprimento de um preceito legal oriunda de um processo de formação descentralizado gera uma lacuna jurídica que beneficia os Estados Nação, pondo em segundo lugar a situação calamitosa dos campos de refugiados, assim como de pessoas rechaçada.

O custo humanitário será muito caro. A situação da Síria, assim como de muitos países do Oriente Médio, será uma mancha indesejada na história mundial. Seguindo a frase de Theodor, "Se os homens não fossem indiferentes uns aos outros, Auschwitz não teria sido possível, os homens não o teriam tolerado. (ADORNO, 2003, p. 119-138)" Analogamente, aos refugiados aplica-se essa regra, pois se não fosse o temor para com povos de diferentes hábitos culturais, e a indiferença para com seus temores, com certeza, a historia tomaria novos relatos. Por hora, a narração segue fria, escura e solitária, tal qual o fundo do mar mediterrâneo.

\section{Referencias}

ACNUR. Convenção Relativa ao Estatuto dos Refugiados. In IDEM. Manual de procedimentos e critérios a aplicar para determinar o estatuto de refugiado. Lisboa: ACNUR, 1996.

ARENDT, Hannah. As origens do totalitarismo. São Paulo: Companhia das Letras, 1989.

ADORNO, Theodor W, Educação após Auschwitz. In: Educação e Emancipação. $3^{\text {a }}$ Ed. São Paulo: Paz e Terra. Tradução de Wolfgang Leo Maar. 
BAUMAN, Zygmunt. Vidas Desperdiçadas. Rio de Janeiro, Jorge Zahar Editor: 2005.

BRAGA, J. L. R. Os campos de refugiados: um exemplo de "espaços de exceção" na política contemporânea. In: $3^{\circ}$ ENCONTRO NACIONAL ABRI 2011. Proceedings online... São Paulo: Associação Brasileira de Relações Internacionais, Instituto de Relações Internacionais - USP, 2011.Disponívelem:

<http://www.proceedings.scielo.br/scielo.php?script=sci_arttext\&pid= MSC0000000122011000200036 \&lng=en\&nrm=abn>. Acesso em: 01 Outubro. 2017.

BRANCOLI, Fernando. Primavera Árabe - praças, ruas e revoltas. São Paulo: Desatino, 2013.

FELLER, E. The Convention at 50: the Way Ahead for Refugee Protection. Forced Migration Review, Oxford, v.10. 2001.

GELVIN, James L. The arab uprisings, what everyone needs to know. Oxford UniversityPress, 2012.

HUMAN RIGHTS WATCH. Waiting here for death: displacement and "villagization" in Ethiopia's Gambella Region. 2012. Disponível em:

<https://www.hrw.org/report/2012/01/16/waiting-here-death/forced-displacement-andvillagization-ethiopias-gambella-region>. Acesso em: 05 Outubro. 2017.

KANT, Imanuel. Crítica da Razão Prática. Tradução de: Artur Mourão. Textos Filosóficos. Lisboa: Edições 70, 1986.

KELSEN, Hans. Teoria Pura do Direito. 7. Ed. São Paulo: Martins Fontes, 2006.

MARX, Karl. Critica a Filosofia do Direito de Hegel. $2^{a}$ ed. Lisboa, Portugal: Presença,1983.

PIOVESAN, Flávia Cristina. Sistema internacional de direitos humanos. I Colóquio Internacional de Direitos Humanos. São Paulo, Brasil, 2001. Disponível em: <http://www.dhnet.org.br/direitos/sip/textos/a_pdf/piovesan_sip.pdf >. Acesso em: 21 Outubro. 2017. 